\title{
Probabilistic fatigue analysis of ultra-high-performance fibre- reinforced concrete under thermal effects
}

\author{
José D. Ríos, Héctor Cifuentes ${ }^{*}$ \\ ETS de Ingeniería, Universidad de SevilPrrla, Camino de los Descubrimientos s/n, 41092, Sevilla, Spain
}

\begin{abstract}
This paper describes the influence of the temperature and the fibre reinforcement on the flexural fatigue behaviour of an ultra-high-performance fibre-reinforced concrete. Three-point bending fatigue tests were carried out for an ultra-high-performance concrete subjected to different temperatures ranging from room temperature up to $300{ }^{\circ} \mathrm{C}$ and considering three different types of reinforcement: a) steel fibres, b) hybrid steel and polypropylene fibres and c) non-reinforced (reference matrix). The fatigue behaviour was assessed from the S-N fields obtained through a probabilistic fatigue model developed by Castillo and Fernández-Canteli. The influence of the type of reinforcement on the fatigue behaviour was analysed by S$\mathrm{N}$ curves. An analysis of the thermal effects in the fatigue life of the ultra-high-performance concrete has also been carried out. The results showed the most suitable fibre reinforcement among the analysed options to get the best fatigue behaviour in accordance to the exposure temperature.
\end{abstract}

\section{Introduction}

Ultra-high-performance fibre-reinforced concrete (UHPFRC) is characterized by a significant enhancement of its mechanical properties, especially the tensile strength, in comparison to conventional or high strength concrete [1]. To achieve this ultra-high strength, a low water-to-binder ratio (usually $w / b \leq 0.2$ ) is used with the addition of ultra-fine admixtures [2], [1]. A denser material is then achieved but with a strongly brittle behaviour. In that way, the addition of steel fibres (in a volume ratio between 2 and $2.5 \%$ ) is essential to obtain a more ductile material and improve the tensile strength [3].

The excellent mechanical properties of this type of concrete lead to a significant reduction in the weight of structures [4]. As result, the application of this type of concrete in situations where traditionally, only metallic materials were used, has been extended. Consequently, the interest in the fatigue analysis of fibre-reinforced concrete has grown significantly, as can be seen from the number of recent works related to the fatigue failure under compressive [5]-[8], tensile [9] or flexural loading [10]-[12]. The most common approach to assess the fatigue life of a material is the stress-life (S-N) curves [13]. In this way, it is possible to design structures under fatigue loads (wind, wave or traffic) by more efficiently designs for each application.

Due to the thermal storage capability of concrete [14], its workability and availability, an emerging technology is the use of concrete as thermal energy storage system in solid media. This technology has attracted great attention by researchers. The most of current studies are mainly focused on the energetic performance of concrete storage systems [15]-[17]. Nevertheless, the main concern of the application of this technology is the durability of concrete due to the degradation of cementitious matrix at moderately high temperatures and the bearing of thermal-mechanical fatigue for long-periods. With respect to the influence of temperature, there are many studies focused on the residual [18]-[23] or hot [20], [24]-[26] mechanical properties of concrete subjected to high temperatures. Other authors have studied the thermal effect on concrete reinforced with polymeric fibres [21], [22], [24], [27] and demonstrated as the addition of polymeric fibres prevent the premature cracking due to pore pressure (spalling) and improve the mechanical properties of concrete at high temperatures [27]-[29]. However, no information is available on the fatigue behaviour of ultra-high-performance fibrereinforced concrete subjected to moderately high temperatures.

In this paper the flexural fatigue behaviour of an ultrahigh-performance fibre-reinforced concrete and its corresponding matrix without any reinforcement are reported in terms of its $\mathrm{S}-\mathrm{N}$ curves at different temperatures (room temperature, $100{ }^{\circ} \mathrm{C}, 200{ }^{\circ} \mathrm{C}$ and 300 $\left.{ }^{\circ} \mathrm{C}\right)$. It was obtained through a probabilistic analysis that the thermal damage in the cement paste strongly decrease the endurance limit and increase the scattering in the S-N curves. On the contrary, the thermal damage leads to a more ductile behaviour of the concrete matrix and consequently to a softer trend of the S-N curves. Spalling effects were observed at $200{ }^{\circ} \mathrm{C}$ for concrete without reinforcement and $300{ }^{\circ} \mathrm{C}$ for concrete with fibre 
reinforcement. The additional reinforcement of concrete with PP micro-fibres was thought as an alternative to improve the fatigue behaviour at higher temperatures and satisfactory results were obtained.

The paper is organized as follows. A description of materials, mix preparation and testing procedure is presented in Section 2. The probabilistic fatigue model is summarized in Section 3. The results and discussion of the influence of the addition of fibres and the temperature on the fatigue life is exposed in Section 4. Finally, conclusions are given in Section 5.

\section{Experimental Program}

\subsection{Materials and Mix Preparation}

The materials consisted of an ultra-high-performance fibre-reinforced concrete (UHC), the same fibrereinforced concrete with additional polypropylene (PP) micro-fibres (UHC_PP) and its corresponding cementitious matrix without any type of reinforcement, used as reference concrete (RC). The mix proportions are given in Table 1. The UHC is reinforced with $2.5 \%$ in volume ratio of steel fibres $(1.25 \%$ of microfibres with $13 \mathrm{~mm}$ in length, $0.2 \mathrm{~mm}$ in diameter and straight end and $1.25 \%$ of macrofibres of $30 \mathrm{~mm}$ in length, $0.38 \mathrm{~mm}$ in diameter and with hooked end).

Table 1. Mix Proportions and Nomenclature

\begin{tabular}{|c|c|c|c|}
\hline Constituent & $\begin{array}{c}\mathrm{RC} \\
\left(\mathrm{kg} / \mathrm{m}^{3}\right)\end{array}$ & $\underset{\left(\mathrm{kg} / \mathrm{m}^{3}\right)}{\mathrm{UHC}}$ & $\underset{\left(\mathrm{kg} / \mathrm{m}^{3}\right)}{\text { UHCPP }}$ \\
\hline Cement & 544 & 544 & 544 \\
\hline Silica fume & 214 & 214 & 214 \\
\hline GGBS & 312 & 312 & 312 \\
\hline $\begin{array}{l}\text { Quartz sand } \\
<0.315 \mathrm{~mm}\end{array}$ & 470 & 470 & 470 \\
\hline $\begin{array}{l}\text { Quartz sand } \\
<0.800 \mathrm{~mm}\end{array}$ & 470 & 470 & 470 \\
\hline Superplasticizer & 42 & 42 & 42 \\
\hline w/binder & 0.17 & 0.17 & 0.17 \\
\hline $\begin{array}{c}\text { Steel microfibre } \\
(13 \mathrm{~mm} \text { in } \\
\text { length })\end{array}$ & - & 98 & 98 \\
\hline $\begin{array}{l}\text { Steel macrofibre } \\
\text { (30 mm in } \\
\text { length) }\end{array}$ & - & 98 & 98 \\
\hline $\begin{array}{l}\text { PP microfibre } \\
\text { (24 mm in } \\
\text { length) }\end{array}$ & - & - & 1.2 \\
\hline
\end{tabular}

The PP micro-fibres were of $24 \mathrm{~mm}$ in length. Four batching's of UHC and RC type of concrete were prepared to be tested under fatigue loading at four different temperature conditions (room temperature, 100 ${ }^{\circ} \mathrm{C}, 200{ }^{\circ} \mathrm{C}$ and $300{ }^{\circ} \mathrm{C}$ ). Two batching's of UHC_PP were casted to be tested at room temperature and $300^{\circ} \mathrm{C}$. The nomenclature of each experimental test is shown in Table 2. All specimens were demoulding after 24 hours of casting, cured in water for 28 days and dried at air after curing process for 24 hours.

Table 2. Nomenclature of Test Conditions

\begin{tabular}{|c|c|c|c|}
\hline & RC & UHC & UHC_PP \\
\hline $\begin{array}{c}\text { Room } \\
\text { temperature }\end{array}$ & RC_RT & UHC_RT & UHC_PP_RT \\
\hline $100^{\circ} \mathrm{C}$ & RC_100 & UHC_100 & - \\
\hline $200^{\circ} \mathrm{C}$ & RC_200 & UHC_200 & - \\
\hline $300^{\circ} \mathrm{C}$ & RC_300 & UHC_300 & UHC_PP_300 \\
\hline
\end{tabular}

\subsection{Three-Point Bending Tests on Prismatic Notched Specimens}

Previously to the fatigue life tests, is required to obtain the monotonic three-point flexural strength. The test was carried out in accordance to the EN-14651 standard [30] for fibre-reinforced concrete. Three-point bending tests were performed on four $440 \times 100 \times 100-\mathrm{mm}$ notched specimens ( $1 / 6$ of height), for each temperature and type of concrete tested, simply supported over a span of 400 $\mathrm{mm}$.

\subsection{Flexural Fatigue Tests on Prismatic Notched Specimens}

The fatigue tests were performed on fourteen prismatic notched specimens subjected to three-point bending tests, as monotonic tests. A servo-hydraulic machine with a $200-\mathrm{kN}$ dynamic-static actuator was used. The frequency of loading and stress ratio were the same for each test, with values of $4 \mathrm{~Hz}$ and 0.2 , respectively. The tests were carried out at different stress levels in the range between 0.5 and 0.9 of the monotonic strength. The tests were stopped after specimen failure or after 2 million cycles, whichever occurred first.

In the cases of the tests at high temperature, the testing equipment was specifically designed to perform the temperature tests, and to insert the hydraulic actuator, the specimen and the supporting structure into the furnace. The heating rate of the specimens was $10{ }^{\circ} \mathrm{C} / \mathrm{min}$ and once the target temperature was reached, it was kept up to 24 hours before starting the fatigue test, to ensure the highest thermal homogeneity in the specimen. 


\section{Probabilistic Fatigue Model Applied}

In this study has been applied a probabilistic fatigue model for the determination of S-N curves proposed by Castillo and Fernandez-Canteli [31]. The probabilistic model allows the assessment of experimental fatigue data to obtain S-N fields. The probabilistic approach of the model, rather than mechanical, makes it suitable for any type of material (ceramic, metallic or concrete) independently of the mechanism of failure [11]. In most of models used, the high scatter of the lifetime at different stress is not considered and that has consequences in the fatigue design of structures. The model used in this study consider both physical (weakest link principle and limited range) and statistical conditions related to extreme value analysis (stability, limit behaviour). The model approach establishes a necessary compatibility between the cumulative distribution functions for fatigue lifetime at given stress range and stress range at given lifetime (Fig .1).

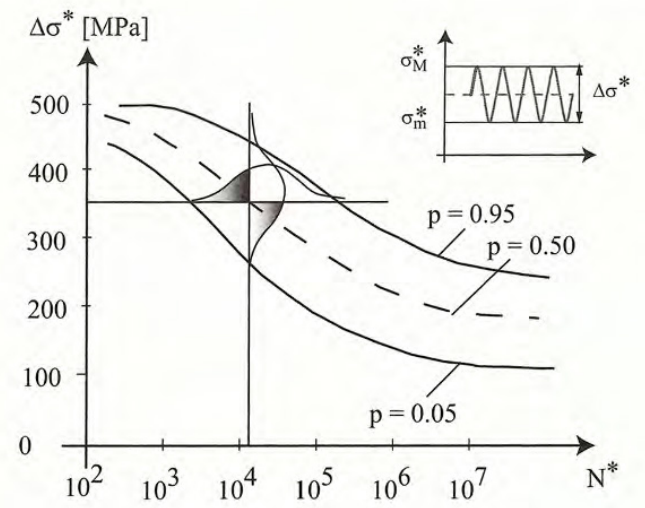

Fig. 1. Compatibility condition approach for the cumulative distribution functions [31].

Such condition derives into a functional equation which only can be solve by a Weibull or Gumbell models:

$$
\begin{aligned}
& p=1-\exp \left[-\left(\frac{N-\lambda}{\delta}\right)^{\beta}\right] ; N \geq \lambda \\
& p=1-\exp \left[-\exp \left(\frac{N-\lambda}{\delta}\right)\right] ; N \in \Re
\end{aligned}
$$

where $B$ is a threshold value of lifetime, $C$ is the endurance limit or fatigue limit for $\mathrm{N} \rightarrow \infty$, and $\lambda, \delta, \beta$ are location, scale and shape Weibull parameters, respectively.

For more information of the probabilistic model is recommended consult Castillo and Fernández-Canteli work [31]. To facilitate the application of the model from experimental fatigue data, Castillo and Fernández-
Canteli developed a software so-called ProFatigue [32] which has been used.

\section{Results and Discussion}

In this study has been shown the effect of fibre reinforcement (for steel and polypropylene fibres) and temperature separately to remark more clearly their influences. With the aim of greater clarity, only the S-N curves for 20 (lower curve) and 80 (upper curve) percentile have been plotted for each type of test. The logarithm of fatigue life, $N$, on $\mathrm{x}$-axis and the stress normalised level, $S$, on y-axis, are plotted.

\subsection{Influence of Fibre Reinforcement}

Fig. 2 shows the S-N curves of UHC and UHC PP at room temperature. The addition of PP fibres in the concrete matrix might decrease the flexural monotonic strength and increase the energy absorption capacity in accordance to the fibre content [33]. In this case the monotonic flexural strength decreased from $26 \mathrm{MPa}$ to $19 \mathrm{MPa}$ which, in the fatigue behaviour derived into a slight reduction of the endurance limit as can be also seen in Table 3 and a softer trend of the S-N curves respectively.

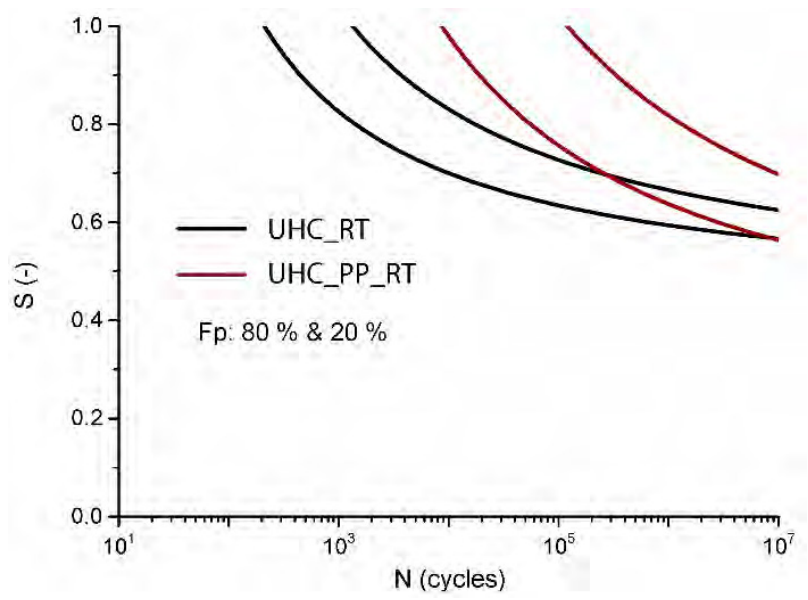

Fig. 2. Influence of PP fibre reinforcement on the S-N curves at room temperature.

Table 3. Endurance Limit

\begin{tabular}{|c|c|c|c|}
\hline & UHC & UHC_PP & RC \\
\hline $\begin{array}{c}\text { Room } \\
\text { temperature }\end{array}$ & 0.488 & 0.375 & 0.210 \\
\hline $100^{\circ} \mathrm{C}$ & 0.263 & no tested & 0.060 \\
\hline $200^{\circ} \mathrm{C}$ & 0.083 & no tested & spalling \\
\hline $300^{\circ} \mathrm{C}$ & spalling & 0.370 & spalling \\
\hline
\end{tabular}


It was well established that the contribution of steel fibres increases the ductile behaviour and the tensile strength [2], [34]. Both effects are shown in the fatigue curves in Fig. 3 by means of a more progressive tendency of the S-N curves and a noticeably higher endurance limit respectively, in comparison with the reference concrete (RC_RT). Nevertheless, the addition of steel fibres might lead to results with a greater scatter, as was postulated by [11], [35] and observed in the higher distance between the S-N curves for UHC_RT.

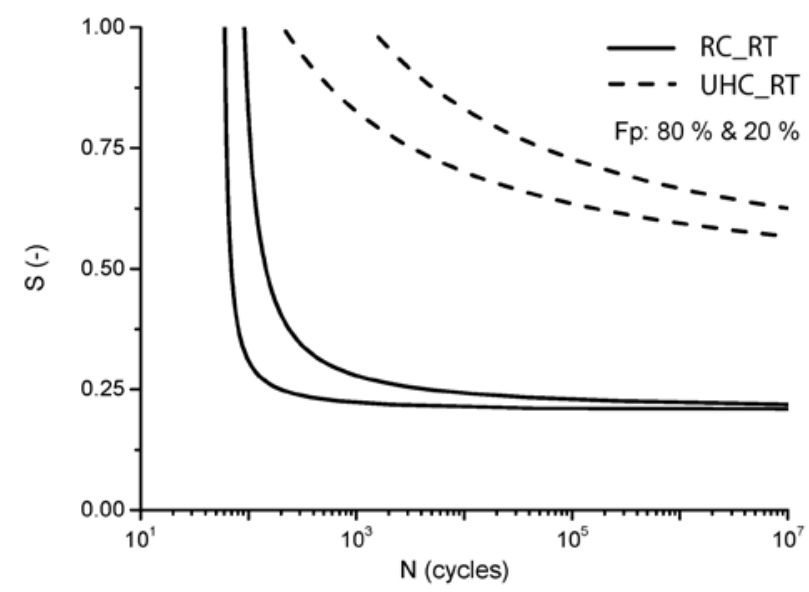

Fig. 3. Influence of steel fibre reinforcement on the S-N curves at room temperature.

\subsection{Influence of Temperature}

The effect of temperature in concrete matrix has been studied in previous works by several authors [36], [37]. Some conclusions extracted from these studies are that between 20 and $110^{\circ} \mathrm{C}$ take place the evaporation of free water and between 160 and $350{ }^{\circ} \mathrm{C}$ an important dehydration derived by C-S-H gel is produced [37]. Both effects lead to a high pressure in the matrix, which generate cracks in concrete (spalling phenomenon). The intensity of thermal damage depends on the concrete matrix, especially its pore network, which allows evacuate the internal high pressure [38].

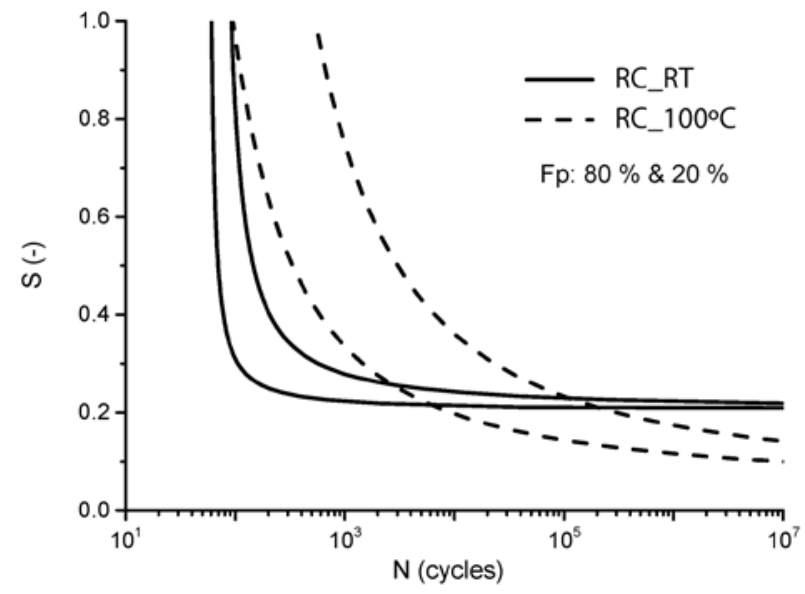

Fig. 4. Effect of temperature on the S-N curves for the RC.
The ultra-high-performance concrete used in this study has a high density (low pore network) which confers excellent mechanical properties but sooner thermal damage. Fig 4. shows the effect of temperature on the reference concrete but only reliable results at room temperature and $100{ }^{\circ} \mathrm{C}$ could be obtained because the spalling appeared from $200{ }^{\circ} \mathrm{C}$ and above. The fatigue life is significantly low at RT because of the brittle behaviour and the absence of barriers (fibre reinforcement) so that when the cracking appears is quickly propagated [39]. The thermal damage, at $100^{\circ} \mathrm{C}$, leads to a lower endurance limit and close to zero which shows as in ultra-high-performance concrete is essential the fibre reinforcement. Additionally, it is observed an increment of scattering by the thermal damage, reflected through the distance between the 80 and 20 percentile S$\mathrm{N}$ curves.

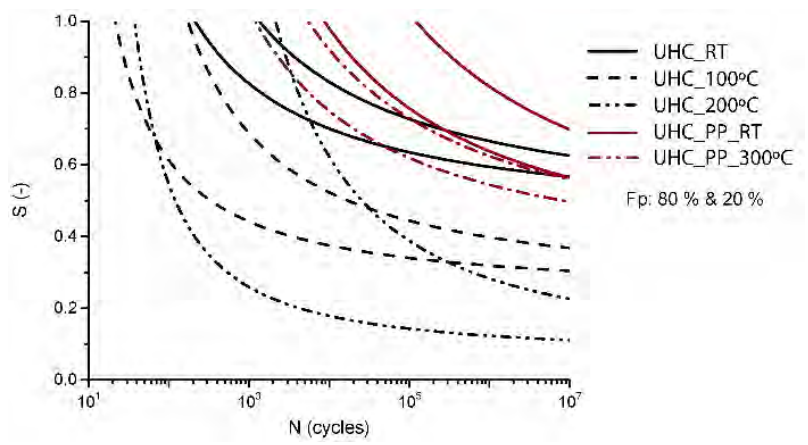

Fig. 5. Effect of temperature on the S-N curves on the UHC and $\mathrm{UHC}$ PP.

Regarding to the effect of temperature on the fibre reinforced concrete (UHC), the observations are qualitatively the same than in RC. Nonetheless, it is worth noting as on the UHC, that significant spalling effects not appear up to $300{ }^{\circ} \mathrm{C}$ because the steel fibres avoid the free propagation of cracks and increase the ductility of the matrix. The scattering inferred by the thermal damage is more relevant than $\mathrm{RC}$ due to the higher temperature reached in the test and the influence of the fibre distribution [35].

The addition of PP micro-fibres in the UHC was needed to reach $300{ }^{\circ} \mathrm{C}$ without spalling failure. The PP fibres are melted at $160{ }^{\circ} \mathrm{C}$ and create a widespread microchannel network which allows the pressure evacuation more easily and delay the spalling [38]. The influence of the addition of PP micro-fibres at RT were discussed in the section 4.1 . At $300{ }^{\circ} \mathrm{C}$, the spalling clearly does not affect and the endurance limit reaches a value very close to the RT. Thus, the addition of PP micro-fibres might be recommended to enhance the fatigue life behaviour at $300^{\circ} \mathrm{C}$. 
[5] G. Ruiz, A. Medeiros, X. X. Zhang, "Experimental Study of Loading Frequency Effect on Compressive Fatigue.", An. Mec.

\section{Conclusions}

From results, the following conclusions can be drawn:

- The addition of steel fibres was essential for the enhancement of the endurance limit and the fatigue life because it avoids the free crack propagation.

- The steel fibre reinforcement slightly increases the scattering of S-N curves due to the fibre distribution.

- The use of PP micro-fibres does not improve the endurance limit at RT but is crucial to reduce spalling effect and to achieve a higher endurance limit at $300{ }^{\circ} \mathrm{C}$.

- The effect of high temperatures is reflected in a damage that infer a significant decrease of the endurance limit and a higher scattering of the S$\mathrm{N}$ curves.

\section{Acknowledges}

Authors would like to acknowledge the financial support from the Ministerio de Economía y Competitividad de España through the projects BIA2016-75431-R.

\section{References}

[1] D. Y. Yoo, N. Banthia, "Mechanical properties of ultra-high-performance fiber-reinforced concrete: A review," Cem. Concr. Compos., 73, (2016).

[2] D. Y. Yoo, S. Kim, G. J. Park, J. J. Park, and S. W. Kim, "Effects of fiber shape, aspect ratio, and volume fraction on flexural behavior of ultra-high-performance fiber-reinforced cement composites," Compos. Struct., 174, (2017).

[3] B. S. Al-Azzawi, B. L. Karihaloo, "Flexural Fatigue Behavior of a Self-Compacting Ultrahigh Performance Fiber-Reinforced Concrete," J. Mater. Civ. Eng., 29, 11, (2017).

[4] C. M. Tam, V. W. Y. Tam, and K. M. Ng, "Assessing drying shrinkage and water permeability of reactive powder concrete produced in Hong Kong," Constr. Build. Mater., 26, 1, (2012).
Fract. 29, 9, (2011)

[6] Y. Chen, J. Ni, P. Zheng, R. Azzam, Y. Zhou, and W. Shao, "Experimental research on the behaviour of high frequency fatigue in concrete," Eng. Fail. Anal., 18, 7, (2011)..

[7] P. B. Cachim, J. A. Figueiras, P. A. A. Pereira, "Fatigue behavior of fiber-reinforced concrete in compression," Cem. Concr. Compos., 24, 2, (2002).

[8] M. Á. Pindado, A. Aguado, A. Josa, "Fatigue behavior of polymer-modified porous concretes," Cem. Concr. Res., 29, 7, (1999).

[9] R. Tepfers, "Tensile Fatigue Strength of Plain Concrete," ACI J. Proc., 76, 8, (1979).

[10] Y. Mohammadi, S. K. Kaushik, "Flexural Fatigue-Life Distributions of Plain and Fibrous Concrete at Various Stress Levels," J. Mater. Civ. Eng., 17, 6, (2005).

[11] J. D. Ríos, H. Cifuentes, R. Yu, G. Ruiz, "Probabilistic Flexural Fatigue in Plain and Fiber-Reinforced Concrete," Materials, 10, 7, (2017).

[12] X. P. Shi, T. F. Fwa, S. A. Tan, "Flexural Fatigue Strength of Plain Concrete,", Materials Journal, 90, (1994).

[13] B. S. Al-Azzawi, B. L. Karihaloo, "Flexural Fatigue Behavior of a Self-Compacting Ultrahigh Performance Fiber-Reinforced Concrete," J. Mater. Civ. Eng., 29, 11, (2017).

[14] M. C. Alonso, J. Vera-Agullo, L. Guerreiro, V. Flor-Laguna, M. Sanchez, M. Collares-Pereira, "Calcium aluminate based cement for concrete to be used as thermal energy storage in solar thermal electricity plants," Cem. Concr. Res., 82, (2016).

[15] E. Özrahat, S. Ünalan, "Thermal performance of a concrete column as a sensible thermal energy storage medium and a heater," Renew. Energy, 111, (2017).

[16] F. Bai, C. Xu, "Performance analysis of a twostage thermal energy storage system using concrete and steam accumulator," Appl. Therm. Eng., 31, 14-15, (2011). 
[17] M. Hazami, S. Kooli, M. Lazâar, A. Farhat, A. Belghith, "Energetic and exergetic performances of an economical and available integrated solar storage collector based on concrete matrix," Energy Convers. Manag., 51, 6, (2010).

[18] F. B. Varona, F. J. Baeza, D. Bru, S. Ivorra, "Influence of high temperature on the mechanical properties of hybrid fibre reinforced normal and high strength concrete," Constr. Build. Mater., 159, (2018).

[19] A. H. Akca, N. Özyurt, "Effects of re-curing on residual mechanical properties of concrete after high temperature exposure," Constr. Build. Mater., 159, (2018).

[20] I. Hager, "Behaviour of cement concrete at high temperature," Bulletin of the Polish Academy of Sciences, 61, (2013).

[21] H. Cifuentes, C. Leiva, F. Medina, C. Fernández-Pereira, "Effects of fibers and rice husk ash on properties of heated high-strength concrete," Mag. Concr. Res., 64, 5, (2012).

[22] T. Drzymała, W. Jackiewicz-Rek, M. Tomaszewski, A. Kuś, J. Gałaj, R. Šukys, "Effects of High Temperature on the Properties of High Performance Concrete (HPC)," Procedia Eng., 172, (2017).

[23] G. F. Peng, W. W. Yang, J. Zhao, Y. F. Liu, S. H. Bian, L. H. Zhao, "Explosive spalling and residual mechanical properties of fibertoughened high-performance concrete subjected to high temperatures," Cem. Concr. Res., 36, 4, (2006).

[24] N. Zhang, B; Bicanic, "Fracture energy of highperformance concrete at high temperatures up to 4508C: the effects of heating temperatures and testing conditions (hot and cold)," Mag. Concr. Res., 58, 5, (2006).

[25] W. Zheng, B. Luo, Y. Wang, "Microstructure and mechanical properties of RPC containing PP fibres at elevated temperatures," Mag. Concr. Res., 66, 8, (2014).

[26] W. Khaliq, V. Kodur, "Thermal and mechanical properties of fiber reinforced high performance self-consolidating concrete at elevated temperatures," Cem. Concr. Res., 41, 11, (2011).

[27] W. Zheng, B. Luo, Y. Wang, "Microstructure and mechanical properties of RPC containing PP fibres at elevated temperatures," Mag. Concr. Res., 66, 8, (2014).
[28] A. H. Akca, N. Ö. Zihnioğlu, "High performance concrete under elevated temperatures," Constr. Build. Mater., 44, (2013).

[29] G-F. Peng, Y-C. Jiang, B-H. Li, J. Zhang, Y-X. Shi, "Effect of high temperature on normalstrength high-performance concrete," Mater. Res. Innov., 18, 2, (2014).

[30] "EN 14651: 2007+A1 Test method for metallic fibered concrete- Measuring the flexural tensile strength (limit of proportionality (LOP), residual), AENOR .," (2007).

[31] E. Castillo, A. Fernandez-Canteli, A unified statistical methodology for modeling fatigue damage. (Springer, 2009) ISBN: 978-1-40209182-7.

[32] A. Fernández-Canteli, C. Przybilla, M. Nogal, M. L. Aenlle, E. Castillo, "Profatigue: A software program for probabilistic assessment of experimental fatigue data sets," Procedia Eng., 74, (2014).

[33] A. A. Ramezanianpour, M. Esmaeili, S. A. Ghahari, M. H. Najafi, "Laboratory study on the effect of polypropylene fiber on durability, and physical and mechanical characteristic of concrete for application in sleepers," Constr. Build. Mater., 44, (2013).

[34] A. Abrishambaf, M. Pimentel, S. Nunes, "Influence of fibre orientation on the tensile behaviour of ultra-high performance fibre reinforced cementitious composites," Cem. Concr. Res., 97, (2017).

[35] E. S. Lappa, (2007) High Strength Fibre Reinforced Concrete: Static and fatigue behaviour in bending. (Thesis dissertation).

[36] A. Lau, M. Anson, "Effect of high temperatures on high performance steel fibre reinforced concrete," Cem. Concr. Res., 36, 9, (2006).

[37] C. Alonso, L. Fernandez, "Dehydration and rehydration processes of cement paste exposed to high temperature environments," J. Mater. Sci., 39, 9, (2004).

[38] H. Cifuentes, F. García, O. Maeso, F. Medina, "Influence of the properties of polypropylene fibres on the fracture behaviour of low-, normaland high-strength FRC," Constr. Build. Mater., 45, (2013). 
[39] R. L. Norton, Machine design. A integrated approach, 5th Editi. (Pearson, 2013) ISBN-13: 978-0133356717. 